
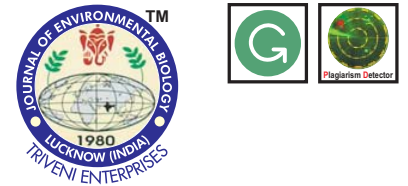

DOI : http://doi.org/10.22438/jeb/38/6(SI)/10

ISSN: 0254-8704 (Print)

ISSN: 2394-0379 (Online)

CODEN: JEBIDP

\title{
Effects of anti-diabetic pharmaceuticals to non-target species in freshwater ecosystems: A review
}

\section{Authors Info}

S.S.S. Sarma* ${ }^{1 *}$ G. García-García S. Nandini ${ }^{1}$ and A.D. SaucedoCampos ${ }^{2,3}$

${ }^{1}$ Laboratory of Aquatic Zoology, National Autonomous University of Mexico, Campus Iztacala, Av. de Los Barrios No.1, AP 314, 54090,

Los Reyes, Tlalnepantla,

State of Mexico, Mexico

${ }^{2}$ Inmunology Laboratory, National Autonomous University of Mexico, Campus Iztacala, Av. de Los Barrios No.1, AP 314, 54090, Los Reyes, Tlalnepantla, State of Mexico, Mexico

${ }^{3}$ Regional Hospital Tlalnepantla ISSEMyM, Av. Indeco 72a, Hab Los Reyes Ixtacala, Barrio de los Árboles / Barrio de los Héroes, 54090 Tlalnepantla, Edo. de, Mexico

${ }^{*}$ Corresponding Author Email : ssssarma@gmail.com

Key words

Emerging pollutant Freshwaters, Insulin Pharmaceuticals Type II diabetes

Publication Info Paper received: 19.01.2017 Revised received : 08.02.2017 Re-revised received : 20.07.2017 Accepted: 09.08.2017

\begin{abstract}
Diabetes Type 2 is among the most common metabolic disorders that human beings face. As the number of diabetic patients increases, the demand for production of antidiabetic drugs also increases. This, in turn, raises environmental concerns since these drugs eventually reach water bodies through various means like, excretory wastes by the patients. It is urgent to make the appropriate legislation to control and regulate the flow of hypoglycemic pharmaceuticals such as metformin into natural lakes and drinking water reservoirs before undesirable and irreversible changes occur in these waterbodies.
\end{abstract}

The use of metformin leads to the environmental release of this drug into the waterbodies. Mexico is one of the nations with the highest number of obese patients and the quantity of metformin administered per patient can be up $2500 \mathrm{mg} /$ day. There are also other products such as alphaglucosidase inhibitors thiazolidinediones, and meglitinides that have the potential to reach aquatic ecosystems. Information related to their concentrations in natural waters, their metabolites or effects on nontarget organisms is scarce. Most studies on the effects of metformin on aquatic organisms have been on fish, algae, and bacteria while zooplankton have received much less attention. This is surprising since zooplankton species are the principal link between phytoplankton and fish larvae and are more sensitive to stress than algae. Flocculation, activated carbon filtration, ozonisation, and chlorination are ineffective in removing metformin and guanylurea. Therefore, other means of waste disposal of unused antidiabetic drugs must be pursued than treating wastewaters containing them.

Metformin and guanylurea are highly water soluble and the available information on the adverse effects of antidiabetic drugs is scarce and restricted to a few groups of aquatic organisms. It is therefore urgently needed to generate appropriate legislation to control and regulate the flow of orally administered pharmaceuticals such as metformin into natural lakes and drinking water reservoirs before undesirable and irreversible changes occur in these waterbodies.

\section{Importance of metformin}

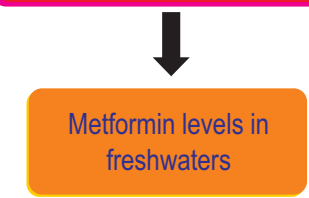<smiles>CN(C)C(=N)NC(=N)Cl</smiles>

Metformin hydrochloride<smiles>N=C(N)NC(N)=O</smiles>

Guanylurea
Trends on metformin research

Ecotoxicological effects of metformin

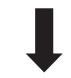

Overview and comments on the fate of antidiabetic drugs 


\section{Introduction}

Type 2 diabetes, usually considered as a result of the metabolic syndrome, is among the most common disorders that human beings face all over the world. Of the 7.5 billion humans on the planet, nearly 420 million people (about $5.5 \%$ ) suffer from this health problem (WHO, 2016), and is currently being considered as a rising pandemic problem. With the availability of selfdetecting diagnostic kits, the global awareness of diabetes is increasing and this, in turn, results in a higher number of diabetic patients reporting to hospitals and private clinics. This increase in the number of diabetic cases has resulted in a demand for higher production of antidiabetic drugs. For example, in Germany, the prescribed metformin almost tripled during the last 10 years and was equivalent to almost 1100 tons in the year 2010 (Schwabe and Paffrath, 2012). Diabetes, technically diabetes mellitus, is related to the high blood glucose which is a lack of production of insulin by the body (Alberti and Zimmet, 1998). There are two main types of this disorder: type 1) common during the paediatric age where insulin is preferably prescribed and the use of metformin is rarely indicated, and type 2) presenting previousresistance to insulin and intolerance to glucose, where oral hypoglycaemic agents are usually used, and metformin is of utmost importance in the treatment. Although there are other varieties such as DM LADA or Mody, considering the scope of this work, these are not elaborated here with respect to their pathophysiology. Nevertheless, these are also usually dependent on the use of oral hypo-glycaemic agents and subcutaneous insulin administration (Anon., 2014). In either case, the medical profession recommends the use of oral antihyperglycemic medicines and/or subcutaneous injection of insulin in addition to other methods of control such as dietary restrictions, exercise etc. More than $90 \%$ of patients suffer from type 2 diabetes and are given hypoglycemic drugs, mostly in the form of tablets (Dunn and Peters, 1995). This, in turn, raises environmental concerns about these hypoglycemic drugs which reach waterbodies through various means: 1) as excretory wastes by the patients (Graham et al., 2011), 2) via landfills where expired medicines are disposed of (Taylor and Senac, 2004) and 3) non-regulatory effluents consisting of both these types of wastes from hospitals (Langford and Thomas, 2009). Metformin is degraded to guanylurea but neither the parent product nor its derivative is removed efficiently from WWTP and therefore persists in the environment with loads ranging in kg/d (Richardson and Kimura, 2015).

Insulin as such poses little threat to aquatic organisms due to its properties. For example, it is largely unstable in the human body or degraded rapidly into oligopeptides and aminoacids (Rabkin et al., 1984) or less stable when stored at high temperature $\left(>32^{\circ} \mathrm{C}\right)$ (Vimalavathini and Gitanjali, 2009). Also, the quantity of insulin injected into the body is very small (generally, a maximum dose of $900 \mu \mathrm{g}$ per day $=300$ units per day). Most applications of insulin for humans are through subcutaneous injection. Thus, commercially available insulin is mostly liquid. Though oral administration of insulin is available, such insulin-containing products are costly, unstable or little used currently in medical procedures; the inhaled insulin, due to uncertainty of regulating its absorption in the body, is currently produced by only a few companies (Gordon Still, 2002). Insulin in a liquid state is less stable and therefore data from the literature on the concentrations of insulin in domestic and hospital effluences are few and toxicity tests are almost non-existent.

Because of the persistence, easy storage, and increased applications, oral antihyperglycemic products such as metformin are gaining importance. The mode of action of metformin is to decrease hepatic glucose production, through the inhibition of the mitochondrial respiratory-chain complex 1 (Viollet et al., 2012). During this process, metformin remains unchanged as it does not undergo hepatic metabolism. Thus, a significant part ( $>90 \%)$ of the absorbed non-metabolized metformin is excreted out within $24 \mathrm{~h}$ mainly through urine by the body's tubular secretion and there is some indication that the average elimination half-life of metformin in plasma is about 6 hours (Scheen, 1996).

In addition to treating diabetic disorders, metformin is also used for treating females with polycystic ovary syndrome, which is the cause of anovulation and infertility (Lord et al., 2003). The doses of metformin in such case can be to the tune of $1500 \mathrm{mg}$ per day. The third well-known application of metformin is for the treatment of obesity (Levri et al., 2005). The use of metformin for curing obesity is based on some evidence that it causes a depletion of adipose tissue but this is not certain (Golay, 2008). Nevertheless, the use of metformin in treating obesity also contributes to the environmental release of this drug into different waterbodies. Incidentally, Mexico is one of the nations with the highest number of obese cases (Wall-Medrano et al., 2016), and became a serious health problem with a considerable impact on paediatric and adult population. The quantity of metformin administered per obese patient per day can be up to $2500 \mathrm{mg}$.

Concentrations of metformin and other oral anti hyperglycemic drugs in freshwaters : During the last two decades, the presence of pharmaceuticals in natural aquatic systems and even in tap waters has been the subject of increasing concern for ecotoxicologists and public health medical officers (Brooks et al., 2009). Some of the pharmaceuticals are non-persistent in water and degrade rapidly but can still pose a threat to aquatic life. For example, even with few hours of half-life in water drugs like ibuprofen and amoxicillin, due to continuous consumption and excretion, can be nearly permanently present in domestic and hospital effluents, thus eventually affecting aquatic organisms (González-Pérez et al., 2016). In addition, some pharmaceuticals such as diethylstilbestroleven at extremely low concentrations of $\mathrm{ng} \mathrm{l}^{-1}$ may still produce adverse effects including hormone mimicking on the reproduction systems (HallingSørensen, 1998). 
Table 1 : Metformin and its metabolite, guanylurea levels $\left(\mathrm{ng} \mathrm{l}^{-1}\right)$ in wastewaters, surface waters and drinking waters from selected parts of the world

\begin{tabular}{|c|c|c|c|c|}
\hline Waste waters & $\begin{array}{l}\text { Surface } \\
\text { water }\end{array}$ & $\begin{array}{l}\text { Drinking } \\
\text { water }\end{array}$ & Location & References \\
\hline \multicolumn{5}{|l|}{ Metformin } \\
\hline \multirow{3}{*}{$3490-88000$} & & & Virginia/USA & Ottmar et al., 2010 \\
\hline & $110-150$ & & US streams & Kolpin et al., 2002 \\
\hline & $110-9200$ & & Lake Michigan & Blair et al., 2013a \\
\hline $3200-100000$ & & & Milwaukee & Blair et al., 2013b \\
\hline \multirow[t]{2}{*}{$>26000$} & $>11000$ & & Jamaica Bay, New York & Benotti and Brownawell, 2007 \\
\hline & $1-2635$ & & North Carolina, South Carolina \& Georgia, USA & Bradley et al., 2016 \\
\hline $28400-67600$ & & & Canada, Saanich Peninsula & James, 2011 \\
\hline $42,000-142300$ & $20-1700$ & $61-292$ & Different waterbodies in Germany & $\begin{array}{l}\text { Scheurer etal., 2009, 2012; Oosterhuis } \\
\text { et al., 2013, Houtman et al., 2013, } \\
\text { Trautwein etal., } 2014\end{array}$ \\
\hline Up to 4040 & & & Portugal, Coimbra hospital effluents & Santos et al., 2013 \\
\hline Up to 1167 & & & Greece & Kosma etal., 2015 \\
\hline \multirow{6}{*}{$20331-94311$} & $<1-6$ & traces & $\begin{array}{l}\text { Dutch waterbodies } \\
\text { Belqium }\end{array}$ & $\begin{array}{l}\text { Derksen and terLaak, } 2013 \\
\text { van Nuiis etal. } 2010\end{array}$ \\
\hline & 100 & 735 & France, Rhônee Alpes region & $\begin{array}{l}\text { van Nuijs et al., } 2010 \\
\text { Vulliet and Cren-Olivé, } 2011\end{array}$ \\
\hline & $100-1,300$ & & Different waterbodies, Switzerland & WIREs Water, 2014 \\
\hline & $240-370$ & & Lake Geneva & WIREs Water, 2014 \\
\hline & Up to 20015 & & China, Tianjin & Kong et al., 2015 \\
\hline & 8250 & & Vietnam, Red river & Chau et al., 2015 \\
\hline $2000-34000$ & $30-130$ & & Different waterbodies in Malaysia & Al-Odaini et al., 2013 \\
\hline $4-31$ & & & Saudi Arabia, Almadinah Almunawarah & Shraim et al., 2017 \\
\hline$>16700$ & & & Australia & Trinh et al., 2011 \\
\hline \multicolumn{5}{|l|}{ Guanylurea } \\
\hline $400-1860$ & & & Germany & Trautwein and Kümmerer, 2011 \\
\hline$<1-99$ & $100-28000$ & & Germany, creeks and rivers & Scheurer etal., 2012 \\
\hline Up to 48010 & & & Germany & Oosterhuis et al., 2013 \\
\hline $900-67200$ & $10-93$ & & Germany & Trautwein et al., 2014 \\
\hline Up to 627 & & & Greece & Kosma et al., 2015 \\
\hline
\end{tabular}

The persistent pharmaceuticals in reservoirs are more problematic since they continuously affect non-target organisms. Metformin, due to its persistence, most of it even after being excreted out still remains in effluents. Table 1 shows the measured concentrations of metformin in inland waters from literature. In effluents, the concentration of metformin can be up to $140 \mu \mathrm{gl}^{-1}$ (Scheurer et al., 2009). Since megacities generate huge quantities of effluents (Mexico City, for example, produces waste water of 75,000 I per second, Monroy et al., 2000), the total quantity of metformin released into waste waters can be several tons per year (Scheurer et al., 2012). Fortunately, in drinking waters, the concentration of metformin can be extremely low $(<1$ $\left.\mu \mathrm{gl}^{-1}\right)$ possibly due to natural microbial degradation or elimination through water treatment (Trautwein and Kümmerer, 2011). However, the degraded products of metformin, e.g., guanylurea are still highly stable and their toxicity to aquatic organisms is still not well-worked out (Richardson and Kimura, 2016). The concentrations of guanylurea in effluents and surface waters can be considerably high $\left(>20 \mu \mathrm{gl}^{-1}\right)$ (Table 1$)$.
In addition to biguanides such as metformin, there are quite a few other products (e.g., thiazolidinediones, alphaglucosidase inhibitors and meglitinides) that are also orally administered to type 2 diabetic patients (Luna and Feinglos, 2001). All these substances also have the potential to reach aquatic ecosystems. However, information related to their concentrations in natural waters, their metabolites or effects on non-target organisms is scarce.

Trends in metformin research : The toxicological or secondary effects of anti-diabetic drugs have received some attention in laboratory evaluations. Published data from the database Biological Abstracts (Thomson Reuters) on metformin research shows that more than $75 \%$ of the works are from endocrinology, pharmacology, nutrition and dietetics and general internal medicine (Fig. 1).

There are also many works (>75\%) evaluating the role of metformin in mammalian systems (humans excluded) but surprisingly only a few of aquatic vertebrates have been 


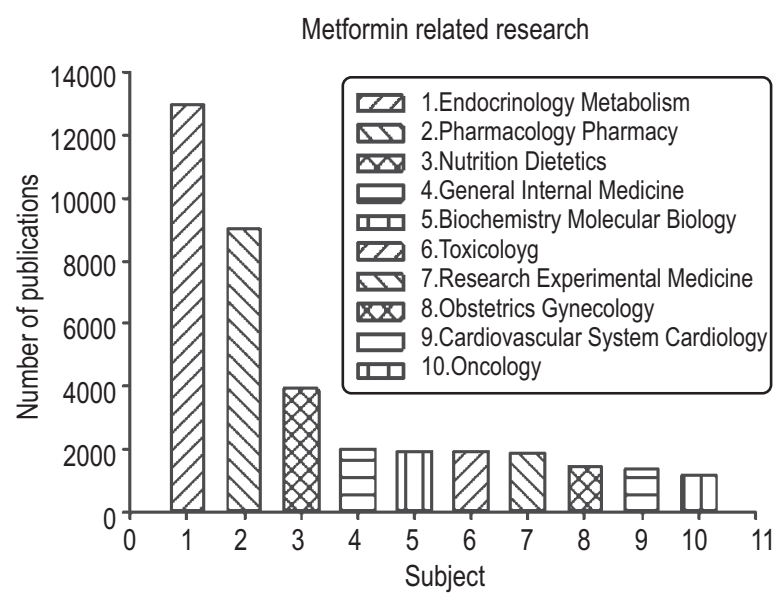

Fig. 1 : Research publications on metformin in different fields of medical and related sciences

considered as a subject of study, in spite of the fact that the metabolized end product finally reaches aquatic ecosystems (Fig. 2). Most studies on the effects of metformin on aquatic organisms have been on fish, algae, and bacteria; species of zooplankton have received considerably much less attention. This is again surprising since zooplankton species are the principal link between phytoplankton and secondary consumers such as fish and are more sensitive to stress than algae (Wallace et al., 2015).

Ecotoxicological effects of antihyperglycemic drugs in freshwaters : Data on the acute and chronic toxicity of antidiabetic medicines including metformin involving different groups of freshwater organisms are reviewed in Caroline et al. (2016). Based on $48 \mathrm{hr}$ acute toxicity tests, it is known that the $\mathrm{EC}_{50}$ of metformin for daphniids is around $60 \mathrm{mg} \mathrm{l}^{-1}$ (Sanderson and Thomsen, 2009). This concentration is an order of magnitude higher than that recorded in effluents or drinking waters (see Table 1). However, metformin, at much lower levels can be detrimental to aquatic organisms.

The solubility of drugs and other pharmaceuticals is an important factor influencing the toxicity to non-target zooplanktonic organisms (Snell and Joaquim-Justo, 2007). Some comparisons of ratios of acute to chronic toxicity to crustaceans and fish from pesticides that have low water solubility or high lipophilic properties have shown no significant differences between them suggesting that the toxic ingredient of the chemical is more important than the solubility (Heger et al., 1995). However, recent reviews suggest that water solubility plays an important role in toxicity testing. For example, if a substance is poorly soluble in water and if no solvent is used to dissolve this prior to preparing a stock solution, then the undissolved substance has no effects on the test species and the expression of final concentrations can be questionable (Weyman

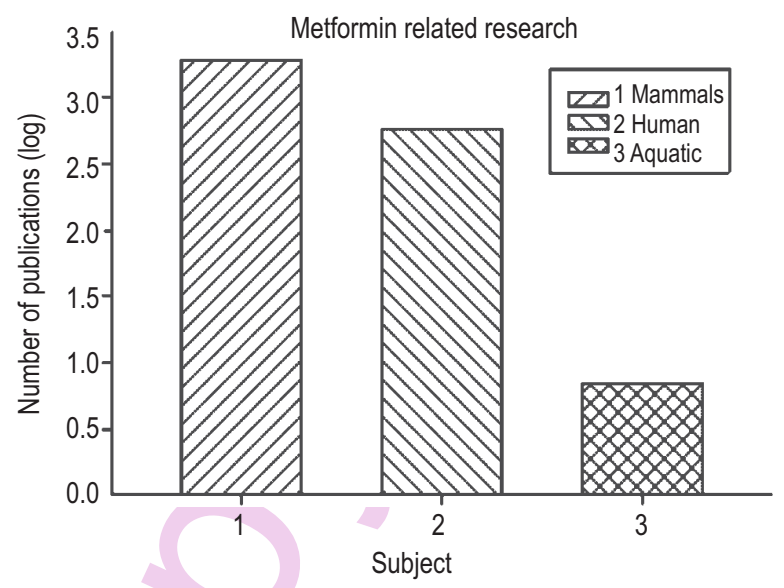

Fig. 2 : Research on metformin in mammals (non-humans), humans and aquatic organisms

et al., 2012). The addition of solvents to dissolve substances with low water solubility also brings other inherent problems including volatility and depletion of dissolved oxygen levels (Lipinski et al., 2001; Weyman et al., 2012). Therefore, for most drugs, water is the preferred solvent by the pharmaceutical industry. Hence metformin and other antihyperglycemic drugs are designed so as to be highly soluble in water. This poses additional problems through effluents for non-target aquatic organisms since the substances remain dissolved in water affecting them directly.

Most aquatic ecotoxicity tests involve plankton species (algae: Nyholm and Källqvist 1989; rotifers: Snell and JoaquimJusto, 2007; cladocerans: Sarma and Nandini 2006; copepods: Kulkarni et al., 2013) as bioassay organisms because of the high population growth rates, sensitivity to stress and ubiquitous distribution (Sarma and Nandini, 2006; Moss, 2014). In addition, due to their ecological role in aquatic systems, they are important indicators of contamination, often the principal target of manmade stressors including effluents of domestic, hospital and industrial origins (González-Pérez et al., 2016). Most phytoplankton species used as bioassay organisms for metformin and other anti-diabetic drugs are the green algae (Chlorophytes), including Selenastrum, Pseudokirchneriella and Scenedesmus (Caroline et al., 2016). These algal species when subject to stress from antihyperglycemic pharmaceuticals, show reduced growth rates or even complete growth inhibition, possibly by accumulation leading to cellular dysfunctions. Morphological changes of algae subject to metformin are scanty because such responses need the application of special techniques, such as electron microscope.

Species of zooplankton are also used in anti-diabetic drug assessment because changes in phytoplankton density affect zooplankton diversity and density (Wetzel, 2001). Of the major groups of zooplankton, ciliates are not widely used in 
toxicity tests involving pharmaceuticals due to their high resistance (Nalecz-Jawecki and Sawicki, 2005). Copepods are also not extensively used in bioassays involving pharmaceutical products due to their predominantly sexual mode of reproduction and complex developmental stages (Marus et al., 2015). On the other hand, both rotifers and cladocerans, reproduce largely by parthenogenesis and lack developmental stages such as naupliar forms (Dodson and Frey, 2001; Wallace et al., 2015). Parthenogenetic mode of reproduction facilitates construction of life tables and estimation of demographic parameters such as age-specific reproduction (Krebs, 1985). Because both rotifers and cladocerans are mainly herbivores feeding on green algae, they can be cultured in large numbers in small volumes; and without losing the population density since they do not show cannibalism. This helps in estimating some other populationrelated parameters such as maximal abundances and the day of peak densities, which are also sensitive to the presence of antidiabetic drugs. For example, García-García et al. (2017) quantified the population response of two rotifer species, Brachionus calyciflorus and Plationus patulus in the presence of metformin at four concentrations ( 25 to $200 \mathrm{mg} \mathrm{l}^{-1}$ ). Their results showed that at $25 \mathrm{mg} \mathrm{l}^{-1}$, metformin had no significant effect on the peak abundances of both the rotifer species. On the other hand, at or higher than $50 \mathrm{mg} \mathrm{l}^{-1}$ of metformin the maximal abundances of $P$. patulus were significantly lower than controls. However, for $B$. calyciflorus significantly lower peak population abundances were observed only at the concentration of $200 \mathrm{mg} \mathrm{l}^{-1}$ of metformin. These results suggest the differences in tolerance levels of the tested rotifer species to drugs.

Long term exposure of zooplankton to low doses of fungicides such as carbendazim and other pollutants results in abnormalities in zooplankton including the formation of intersexes (Ignace et al., 2011; Miracle et al., 2011). Prolonged exposure of fish to antidiabetic drugs is also known to result in developmental abnormalities, which cannot be assessed in short term tests. For example, in the temperate freshwater fish Pimephales promelas exposed to metformin for a year resulted in intersex gonads in some individuals while males were reduced in size (Niemuth and Klaper, 2015). It is possible other species of aquatic or semi-aquatic vertebrates such as frogs and salamanders that develop in freshwaters may also show developmental abnormalities. Quantitative data for these groups exposed to metformin or other antidiabetic drugs are lacking.

The mode of action of metformin in reducing the blood sugar levels in humans is quite well-described. It decreases the production of glucose in the liver. It also results in decreased absorption of glucose in the intestine. Finally, metformin enhances insulin sensitivity through higher glucose uptake by muscles (Wilcox, 2005). Such mechanisms certainly do not operate in zooplankton as they are evolutionarily primitive. There is some suggestion that metformin results in decreased food intake in humans (Lee and Morley, 1998). It is possible that zooplankton may also show decreased food intake when exposed to pharmaceuticals because filtration systems in rotifers and cladocerans are sensitive to stress (Snell and JoaquimJusto, 2007; Suhett et al., 2015).

Methods of removal of antidiabetic drugs such as metformin from wastewaters or from drinking waters can be expensive or unsuccessful. For example, flocculation and activated carbon filtration are ineffective for removing metformin and guanylurea; ozonisation and chlorination in wastewater treatment plants are also not rewarding as these chemicals partly transformed to yet unknown compounds (Scheurer et al., 2012). Therefore, other means of waste disposal of unused antidiabetic drugs (e.g., depositing in specific containers) are both economically and technically more viable than treating wastewaters containing them.

In general, widely used pharmaceuticals with and without the necessity of medical prescriptions, have received considerable attention from aquatic ecotoxicologists. However, metformin, which is one of the drugs with the highest consumption rates of all pharmaceuticals worldwide, is still poorly investigated in terms of its environmental fate and effects on non-target organisms (Scheurer et al., 2012). In the Netherlands, metformin and its degraded product guanylurea make up $>50 \%$ of all pharmaceuticals together in wastewaters (STOWA, 2013). In many countries including Mexico the effluent treatment plants never meet the full requirement of treating wastewater and a great quantity of partially treated or untreated wastewater containing resistant pharmaceuticals, are directly discharged into freshwater ponds, lakes or even drinking water reservoirs with undesirable or unknown consequences to plankton and other aquatic organisms (Nandini et al., 2016). Metformin together with its metabolite, guanylurea, are highly water soluble and therefore are less likely to be deposited in the sediments. In addition, the available information on the adverse effects of antidiabetic drugs is not only scarce but also restricted to only a few groups of aquatic organisms such as fish, while the sensitivity of other taxa including plankton, which are more diverse and abundant, are rarely considered. It is therefore urgently needed to make appropriate legislation to control and regulate the flow of resistant antidiabetic pharmaceuticals such as metformin into natural lakes and drinking water reservoirs before undesirable and irreversible changes occur in these waterbodies.

\section{Acknowledgment}

This work was supported by a project from PAPIIT-IA203315.

\section{References}

Alberti, K.G.M.M. and P.F. Zimmet: Definition, diagnosis and classification of diabetes mellitus and its complications. Part 1: Diagnosis and classification of diabetes mellitus. Provisional report of a WHO consultation. Diab. Med., 15, 539-553 (1998). 
Anonymous: American Diabetes Association: Diagnosis and classification of diabetes mellitus. Diab. Care, 37, S81-S90 (2014).

Brooks, B.W., D.B. Huggett and A.B.A. Boxall: Pharmaceuticals and personal care products: research needs for the next decade. Environ. Toxicol. Chem., 28, 2469-2472 (2009).

Dodson, S.I. and D.G. Frey: The Cladocera and other Branchiopoda. In: Ecology and Systematics of North American Freshwater Invertebrates (Eds.: J.E. Thorpe and A.P. Covich). $2^{\text {nd }}$ Edn., Academic Press, New York, pp. 849-913 (2001).

Dunn, C.J. and D.H. Peters: Metformin. A review of its pharmacological properties and therapeutic use in non-insulin-dependent diabetes mellitus. Drugs, 49, 721-749 (1995).

García-García, G., G.I. Reyes-Carrillo, S.S.S. Sarma and S. Nandini: Population level responses of rotifers (Brachionus calyciflorus and Plationus patulus) to the anti-diabetic drug, metformin. J. Environ. Biol., 38 (Special issue), 1213-1219(2017).

Golay, A.: Metformin and body weight: Review. Int. J. Obe., 32, 61-72 (2008).

González-Pérez, B.K., S.S.S. Sarma and S. Nandini: Effects of selected pharmaceuticals (ibuprofen and amoxicillin) on the demography of Brachionus calyciflorus and Brachionus havanaensis (Rotifera). Egy. J. Aqu. Res., 42, 341-347 (2016).

Gordon, S.J.: Development of oral insulin: progress and current status. Diabetes Metab. Res. Rev.,18, S29-S37 (2002).

Graham, G.G., J. Punt, M. Arora, R.O. Day, M.P. Doogue, J.K. Duong, T.J. Furlong, J.R. Greenfield, L.C. Greenup, C. M. Kirkpatrick, J.E. Ray, P. Timmins and K.M. Williams: Clinical pharmacokinetics of metformin. Clinical Pharmacokinetics, 50, 81-98 (2011).

Krebs, C.J.: Ecology: the experimental analysis of distribution and abundance. $3^{\text {rd }}$ Edn., New York: Harper and Row, p. 800 (1985).

Kulkarni, D., A. Gergs, U. Hommen, H.T. Ratte and T.G. Preuss: A plea for the use of copepods in freshwater ecotoxicology. Environ. Sci. Pollut. Res. Int., 20, 75-85 (2013).

Langford, K.H. and K.V. Thomas: Determination of pharmaceutical compounds in hospital effluents and their contribution to wastewater treatment works. Environ. Int., 35, 766-770 (2009).

Lee, A. and J.E. Morley: Metformin decreases food consumption and induces weight loss in subjects with obesity with type II non-insulindependent diabetes. Obes. Res., 6, 47-53. (1998).

Levri, K.M., E. Slaymaker, A. Last, J. Yeh, J. Ference, F. D'Amico and S.A. Wilson: Metformin as treatment for overweight and obese adults: Asystematic review. Ann. Fam. Medi., 3, 457-461 (2005).

Lord, J.M., I.H.K. Flight and R.J. Norman: Metformin in polycystic ovary syndrome: Systematic review and meta-analysis. Brit. Med. J., 327, 951 (2003).

Luna, B. and M.N. Feinglos: Oral agents in the management of Type 2 diabetes mellitus. Am. Fam. Physician,63, 1747-1756 (2001).

Marus, E.M., J.R. Elphick and H.C. Bailey: A new toxicity test using the freshwater copepod Cyclops vernalis. Bull. Environ. Contam. Toxicol., 95, 357-362 (2015).

Nalecz-Jawecki, G. and J. Sawicki: Influence of water hardness on the toxicity of selected pharmaceuticals and metals to the protozoa Spirostomum ambiguum and Tetrahymena termophila. Fresen Environ. Bull., 14, 873-877 (2005).
Nandini, S., P. Ramírez-García and S.S.S. Sarma: Water quality indicators in Lake Xochimilco, Mexico: Zooplankton and Vibrio cholera. J. Limnol., 75, 91-100 (2016).

Niemuth, N.J. and R.D. Klaper: Emerging wastewater contaminant metformin causes intersex and reduced fecundity in fish. Chemosphere, 135, 38-45 (2015).

Nyholm, N. and T. Källqvist: Methods for growth inhibition toxicity tests with freshwater algae. Environ. Toxicol. Chem., 8, 689-703 (1989).

Rabkin, R., M.P. Ryan and W.C. Duckworth: The renal metabolism of insulin. Diabetologia, 27, 351-357 (1984).

Richardson, S.D. and S.Y. Kimura: Water Analysis: Emerging Contaminants and Current Issues. Anal. Chem., 88, 546-82 (2016).

Scheen, A.J.: Clinical pharmacokinetics of metformin. Clinical Pharmacokinetics, 30, 359-371 (1996).

Snell, T.W. and C. Joaquim-Justo: Workshop on rotifers in ecotoxicology. Hydrobiologia, 593, 227-232 (2007).

Suhett, A.L., J.M. Santangelo, R.L. Bozelli, C.E.W. Steinberg and V.F. Farjalla: An overview of the contribution of studies with cladocerans to environmental stress research. Acta Limnologica Brasiliensia, 27, 145-159 (2015).

Taylor, D. and T. Senac: Human pharmaceutical products in the environment - The "problem" in perspective. Chemosphere, 115, 95-99 (2004).

STOWA: Human pharmaceuticals in the water cycle. The Foundation for Applied Water Research Report 2013-23. Amersfoort, Utrecht, The Netherlands, p. 66 (2013).

Trautwein, C. and K. Kümmerer: Incomplete aerobic degradation of the antidiabetic drug metformin and identification of the bacterial dead-end transformation product Guanylurea. Chemosphere, 85, 765-73 (2011).

Vimalavathini, R. and B. Gitanjali: Effect of temperature on the potency and pharmacological action of insulin. Indian J. Med. Res., 130, 166-169 (2009).

Viollet, B., B. Guigas, S.N. Garcia, J. Leclerc, M. Foretz and F. Andreelli: Cellular and molecular mechanisms of metformin: An overview. Clin. Sci., 122, 253-270 (2012).

Wallace, R.L., T.W. Snell and H.A. Smith: Phylum Rotifera. In: Ecology and General Biology (Eds.: J. Thorp and D.C. Rogers). Thorp and Covich's Freshwater Invertebrates, Academic Press, pp. 225-271 (2015).

Wall-Medrano, A., A. Ramos-Jiménez, R.P. Hernandez-Torres, R. Villalobos-Molina, D.C. Tapia-Pancardo, J.R. Jiménez-Flores, A.R. Méndez-Cruz, M. Murguía-Romero, I.A. Gallardo-Ortíz and R. Urquídez-Romero: Cardiometabolic risk in young adults from northern Mexico: Revisiting body mass index and waistcircumference as predictors. BMC Public Hlth., 16, 236 DOI: 10.1186/s12889-016-2896-1 (2016).

Wetzel, R.G.: Limnology: Lake and River Ecosystems. $3^{\text {rd }}$ Edn., Academic Press, London, p. 1006 (2001).

WHO: Global report on diabetes. World Health Organization, Geneva (2016).

Wilcox, G.: Insulin and Insulin Resistance. Clinical Biochemist Reviews, 26, 19-39(2005). 